\title{
Substratos alternativos na clonagem de faveleira (Cnidoscolus quercifolius) pela técnica de alporquia
}

\author{
Maria Nilvânia da Silva Noberto ${ }^{1}$, Eder Ferreira Arriel ${ }^{1 *}$, Antonio Lucineudo de Oliveira Freire1, Diércules \\ Rodrigues dos Santos ${ }^{1}$, José Aminthas de Farias Júnior ${ }^{1}$, Assíria Maria Ferreira da Nóbrega ${ }^{1}$
}

RESUMO: Cnidoscolus quercifolius Pohl (faveleira) é espécie arbórea nativa do bioma Caatinga, amplamente utilizada pelas populações locais inseridas neste bioma, no tratamento de processos inflamatórios. Esta pesquisa teve por objetivo avaliar a ausência e presença de ácido indol butírico $\left(6,0 \mathrm{~g} \mathrm{~L}^{-1}\right.$ de AIB) e seis substratos, compostos de fibra da casca de coco verde, pó da casca de coco verde e rejeito de vermiculita na produção de mudas de faveleira pela técnica clonal de alporquia. Observações semanais na superfície do substrato foram realizadas para detectar o surgimento de raízes no alporque, até 90 dias. Os ramos com os alporques foram removidos e coletados os seguintes dados: alporques sem calos; alporques com calos (formação de massa celular indiferenciada na região do anelamento); alporques com primórdios radiculares e alporques enraizados. Nos alporques enraizados, analisou-se o número de raízes, comprimento da maior raiz $(\mathrm{cm})$ e massa seca das raízes $(\mathrm{g})$. Por meio da contagem dos alporques enraizados foi calculada a porcentagem de enraizamento dos alporques. $\mathrm{O}$ uso do AIB foi eficiente no incremento do comprimento, número e massa seca de raízes. O substrato com $1 / 3$ de fibra da casca de coco verde $+1 / 3$ de pó da casca de coco verde $+1 / 3$ de rejeito de vermiculita é o mais eficiente para o enraizamento de alporques em ramos de faveleira e de baixo custo.

Palavras-chave: Propagação vegetativa, propagação clonal, medicina popular, impacto ambiental.

\section{Alternative substrates in cloning faveleira (Cnidoscolus quercifolius) by the technique of air layering}

\begin{abstract}
Cnidoscolus quercifolius Pohl (faveleira) is a native tree species of the Caatinga biome, widely used by the local populations inserted in this biome, in the treatment of inflammatory processes. The objective of this study was to evaluate the absence and presence of indole butyric acid $\left(6.0 \mathrm{~g} \mathrm{~L}^{-1}\right.$ of IBA) and six substrates, green coconut shell (CF) fiber compounds, and vermiculite tailings (RV) in the production of faveleira seedlings by the clonal technique of air layering. Weekly observations on the surface of the substrate were performed to detect the appearance of roots in the air layering, up to 90 days. The branches with the air layering were removed and collected the following data: air layering without corns; air layering with callus (formation of undifferentiated cell mass in the ring region); air layering with root primordia and rooted air layering. In rootstocks, the number of roots, root length (cm) and root dry mass ( $\mathrm{g}$ ) were analyzed. By means of the count of the rooted air layering the percentage of rooting of the air layering was calculated. The use of AIB was efficient in increasing the length, number and dry mass of roots. The substrate with $1 / 3$ of the fiber of the green coconut shell $+1 / 3$ of the powder of the green coconut shell $+1 / 3$ of vermiculite tailings is the most efficient for the rooting of air layering in bouquets and low cost.
\end{abstract}

Keywords: Vegetative propagation, clonal propagation, folk medicine, environmental impact.

\section{INTRODUÇÃO}

Cnidoscolus quercifolius Pohl (faveleira) é espécie arbórea nativa do bioma Caatinga, pertencente à família Euphorbiaceae, amplamente utilizada pelas populações locais inseridas neste bioma (PAULINO et al., 2011; MARREIROS et al., 2015). Pesquisas com cobaias comprovaram o efeito anti-inflamatório do extrato etanólico de cascas e folhas de faveleira (GOMES et al., 2014). Estas partes da planta podem ser utilizadas no tratamento de processos inflamatórios do ovário, próstata (AGRA et al., 2007), dentes, coluna (ROQUE et al., 2010) e úlceras (FRANÇA et al., 2008). No entanto, a casca e a entrecasca, que correspondem ao ritidoma, periderme, floema e ao câmbio do tronco da árvore são as partes mais procuradas pelos herbolários para os preparos de fármacos tradicionais (MARREIROS et al., 2015), em virtude de estarem disponíveis durante todo ano. A presença de folhas, flores e frutos são observadas apenas na estação chuvosa, que é concentrada em apenas quatro meses do ano, na região de ocorrência da espécie.

Como a retirada da parte externa do tronco pelos herbolários atinge o câmbio, consequentemente, a planta não resiste resultando em morte do indivíduo. Para atenuar este impacto ambiental, é necessário 
que seja realizada a implantação de áreas para a exploração desta espécie que tem potencial de agregação de renda, melhoria da saúde familiar, redução do desemprego e da fome de milhares de famílias na região nordeste do Brasil (FARIAS JÚNIOR et al., 2015).

A produção de mudas de origem seminal é difícil devido à dispersão ser autocórica, lançando as sementes a uma determinada distância, onde, boa parte delas é consumida pela fauna da Caatinga (PIMENTA et al., 2014). O uso da técnica de estaquia foi estudado por Silva et al. (2013) com pouco sucesso devido a espécie ser de difícil enraizamento. Uma alternativa é o uso da técnica de clonagem denominada alporquia, devido seu maior sucesso em espécies de difícil enraizamento adventício (LEITE et al., 2007; REHMAN et al., 2013).

A aplicação desta técnica de clonagem de plantas foi recomendada para a espécie Blighia sapida L. por Maurya et al. (2013) com o objetivo de reduzir o período juvenil, menor custo em relação a técnica da enxertia, dificuldade de enraizamento por estaquia, demora, baixa taxa germinação e heterogeneidade no tamanho dos frutos com o uso da propagação seminal.

Outra aplicação promissora desta técnica, avaliada para espécie Bixa orellana L. (urucum), foi sugerida por Mantovani et al. (2010), como uma importante ferramenta a ser utilizada na área da biotecnologia moderna. Há genótipos superiores adultos que são de difícil propagação pela técnica da estaquia, sendo necessário preliminarmente o resgate destes genótipos pela técnica de cultivo "in vitro". De acordo com os autores, a presença de microorganismos como os fungos e bactérias, que ocorrem especialmente em explantes oriundos de plantas adultas em condições de campo, provocam elevados níveis de contaminação do material vegetal quando cultivado in vitro. $\mathrm{O}$ resgaste pela técnica da alporquia possibilita a manutenção de genótipos superiores rejuvenescidos em casa de vegetação, sob controle fitossanitário e nutricional. O manejo dessas plantas possibilita mantê-las como minicepas fornecedoras de propágulos vegetativos, tais como segmentos nodais, que poderão ser utilizados como explantes no cultivo in vitro ou como miniestacas.

Substratos como fibra e pó da casca de coco verde e rejeito de vermiculita surgem como alternativas economicamente viáveis a serem pesquisadas para a composição de substratos, a serem usados neste processo de clonagem de plantas. Com o uso destes materiais, é possível reduzir o custo na produção de mudas por ser de fácil aquisição e ao mesmo tempo contribui para a mitigação dos impactos ambientais, causados pela deposição destes produtos no meio ambiente.
A casca de coco verde, além da importância econômica, social e ambiental, é viável como substrato por ser quase inerte, apresentar alta porosidade, fácil produção, baixo custo e alta disponibilidade (CARRIJO et al., 2002). Grandes concentrações de taninos solúveis em fibra de coco inibem o crescimento das raízes. Por meio da lavagem da casca de coco verde com água de boa qualidade, é possível reduzir os níveis tóxicos de tanino, cloreto de potássio e de sódio (CARRIJO et al., 2002). Condutividade elétrica (CE) maior que 3,0 dS/m limita o crescimento da maioria das plantas e, quando se trata de espécies mais sensíveis à salinidade, o valor deve ser inferior a $1,0 \mathrm{dS} / \mathrm{m}$ (ROSA et al., 2001).

$\mathrm{O}$ rejeito de vermiculita é um material inerte, que é descartado no beneficiamento da vermiculita e fica depositado nas proximidades das minas, sem nenhuma utilidade, gerando cerca de um milhão de toneladas ao longo de uma década (VIEIRA, 2003).

$\mathrm{O}$ uso do rejeito de vermiculita como substrato alternativo promoveu bom desempenho no enraizamento adventício, quando foi avaliado por Farias Júnior et al. (2015), na produção de mudas de faveleira clonadas por alporquia. No entanto, em virtude da alta densidade deste substrato, provocou perdas de alporques por meio da quebra de ramos alporcados. Uma alternativa é avaliar o rejeito, em composição com a casca de coco que tem densidade baixa.

De acordo com Dutra et al. (2012), as auxinas sintéticas são usadas como indutores que favorecem o balanço hormonal e promovem o enraizamento em alporques. Sigh e Ansari (2014) constataram eficiência do uso de reguladores de crescimento na promoção do enraizamento nas espécies tropicais Boswellia serrata e Dalbergia sissoo. Entre as auxinas utilizadas como indutor de enraizamento, o ácido indolbutírico (AIB) é o mais recomendado. Maurya et al. (2013) obtiveram $100 \%$ de enraizamento na espécie Blighia sapida L. com o uso de uma concentração de $3,5 \mathrm{~g} \mathrm{~L}^{-1}$ de AIB.

Diante do exposto, esta pesquisa teve por objetivo avaliar a ausência e presença de ácido indol butírico (6,0 g L-1 de AIB) e seis substratos, compostos de fibra da casca de coco verde, pó da casca de coco verde e rejeito de vermiculita na produção de mudas de faveleira pela técnica clonal de alporquia.

\section{METERIAL E MÉTODOS}

Ramos de Cnidoscolus quercifolius Pohl (Euphorbiaceae) com folhas, flores e frutos foram coletados de plantas localizadas na Fazenda NUPEÁRIDO (Núcleo de Pesquisa para o Trópico Semiárido), pertencente ao Centro de Saúde e Tecnologia Rural da Universidade Federal de 
Campina Grande (CSTR/UFCG). O material foi prensado e, em seguida, levado para secagem em estufa a $60 \pm 0,5{ }^{\circ} \mathrm{C}$. Após a secagem, confeccionaram-se as exsicatas, e estas foram registradas no Programa Brahms. O material encontra-se depositado no Herbário do CSTR/UFCG sob o registro $\mathrm{N}^{\circ} 3820$.

$\mathrm{O}$ ácido indolbutírico (AIB) foi avaliado na concentração de $6,0 \mathrm{~g} \mathrm{~L}^{-1}$, além da testemunha (sem AIB). Salienta-se que ácido indolbutírico (AIB) foi avaliado na concentração de $6,0 \mathrm{~g} \mathrm{~L}^{-1}$, por ter apresentado o melhor resultado na indução de enraizamento em faveleira (CAMPOS et al., 2015).

Os substratos foram compostos de fibra da casca de coco verde (FC), pó da casca de coco verde (PC) e rejeito de vermiculita (RV), puros e em frações combinadas. A combinação dos dois fatores (substratos e AIB) totalizaram 12 combinações avaliadas ( Tabela 1).

Tabela 1. Substratos e doses de AIB avaliados em alporques de C. quercifolius.

Substratos*

FC

PC

$\mathrm{RV}$

$1 / 2 \mathrm{FC}+1 / 2 \mathrm{RV}$

$1 / 2 \mathrm{PC}+1 / 2 \mathrm{RV}$

$1 / 3 \mathrm{FC}+1 / 3 \mathrm{PC}+1 / 3 \mathrm{RV}$

Doses de AIB

Testemunha $\left(0,0 \mathrm{~g} \mathrm{~L}^{-1}\right)$

$\operatorname{AIB}\left(6,0 \mathrm{~g} \mathrm{~L}^{-1}\right)$

Testemunha $\left(0,0 \mathrm{~g} \mathrm{~L}^{-1}\right)$

AIB $\left(6,0 \mathrm{~g} \mathrm{~L}^{-1}\right)$

Testemunha $\left(0,0 \mathrm{~g} \mathrm{~L}^{-1}\right)$

$\operatorname{AIB}\left(6,0 \mathrm{~g} \mathrm{~L}^{-1}\right)$

Testemunha $\left(0,0 \mathrm{~g} \mathrm{~L}^{-1}\right)$

$\operatorname{AIB}\left(6,0 \mathrm{~g} \mathrm{~L}^{-1}\right)$

Testemunha $\left(0,0 \mathrm{~g} \mathrm{~L}^{-1}\right)$

$\operatorname{AIB}\left(6,0 \mathrm{~g} \mathrm{~L}^{-1}\right)$

Testemunha $\left(0,0 \mathrm{~g} \mathrm{~L}^{-1}\right)$

$\operatorname{AIB}\left(6,0 \mathrm{~g} \mathrm{~L}^{-1}\right)$

* FC: Fibra de coco; PC: Pó de coco; RV: Rejeito de vermiculita.

A fibra e o pó da casca de coco verde foram adquiridos no Centro de Referência para a Recuperação de Áreas Degradadas da Caatinga (CRAD), situada na Universidade do Vale do São Francisco (UNIVASF), no município de Petrolina, PE. O rejeito de vermiculita foi obtido na mina Pedra Lavrada, localizada no município de Santa Luzia, PB.

Visando reduzir as concentrações de taninos solúveis, a lavagem da fibra e do pó de coco verde foi realizada de acordo com os procedimentos recomendados por Rosa et al. (2001). Após a lavagem foram verificados valores da CE de 0,12 e 0,063 para o pó e a fibra, respectivamente.

Cada alporque recebeu $600 \mathrm{~cm}^{3}$ de substrato. Para a manutenção da umidade utilizou-se quantidade suficiente de água para mantê-lo com uma retenção de água correspondente a $70 \%$ da capacidade de retenção do substrato, deixando $30 \%$ dos poros dos substratos para aeração (LUCENA et al., 2014).

Para a preparação do AIB, foi adotada a metodologia de Campos et al. (2015), ou seja, soluções hidroalcoólicas $(50 \% \quad \mathrm{v} / \mathrm{v})$ nas concentrações 0,0 e $6,0 \mathrm{~g} \mathrm{~L}^{-1}$ foram preparadas.

Foram utilizadas dezesseis matrizes que apresentavam ramos e folhas saudáveis e vigorosos. Os ramos utilizados para os alporques apresentaram diâmetro entre 1 e $2 \mathrm{~cm}$. Os ramos foram anelados utilizando um canivete, removendo-se completamente a casca, formando um anelamento de $1,5 \mathrm{~cm}$ de largura, a uma distância de $45 \mathrm{~cm}$ abaixo do ápice dos mesmos. Na porção anelada foi aplicado o AIB, com auxílio de um pincel, na concentração de $6,0 \mathrm{~g} \mathrm{~L}^{-1}$, e, para a testemunha, a solução hidroalcoólica. Em seguida, foi introduzido ao ramo um tubo de filme de polietileno, nas dimensões de $200 \mathrm{~mm}$ x $360 \mathrm{~mm}$ e $0,18 \mathrm{~mm}$ de espessura. O filme foi amarrado em uma das extremidades ao ramo, abaixo do anelamento, e foi preenchido com substrato previamente umedecido.

Logo após, a extremidade superior do filme de polietileno também foi amarrada ao ramo, a fim de criar um ambiente úmido e escuro ao redor do anelamento. $\mathrm{O}$ alporque foi identificado com uma etiqueta de polietileno. Cada alporque foi envolvido com papel alumínio para impedir o contato do substrato com os raios solares, para reduzir a temperatura no interior do substrato e repelir insetos que danificam os alporques. Para a coleta de dados, foram adotados os procedimentos recomendados por Farias Júnior et al. (2015). Após o início da instalação do experimento, observações semanais na superfície do substrato foram realizadas, a fim de observar o surgimento de raízes no alporque até os 90 dias. Em seguida, os ramos alporcados foram 
removidos das plantas matrizes, com o auxílio de tesoura de poda, e levados para o Laboratório de Fisiologia Vegetal do CSTR/UFCG, sendo retirados os substratos com a lavagem das raízes (quando presentes) para a coleta dos seguintes dados: alporques sem calos; alporques com calos (formação de massa celular indiferenciada na região do anelamento); alporques com primórdios radiciais e alporques enraizados. Nos alporques enraizados, analisou-se o número de raízes, comprimento da maior raiz $(\mathrm{cm})$ e massa seca das raízes $(\mathrm{g})$. Por meio da contagem dos alporques enraizados foi calculada a porcentagem de enraizamento dos alporques.

As variáveis alporques sem calos; alporques com calos (formação de massa celular indiferenciada na região do anelamento); alporques com primórdios radiciais, alporques enraizados e comprimento da maior raiz por alporque foram avaliadas por meio de atribuição de notas aos alporques em uma escala de 0 (zero) a 4 (quatro), conforme proposto por Brito et al. (2014): sendo 0 (zero), alporque sem calos; 1 (um), alporque com formação de calo; 2 (dois), alporque com primórdios radiciais; 3 (três), alporque com raiz até $4 \mathrm{~cm}$ e 4 (quatro), alporque com raiz maior que $4 \mathrm{~cm}$.

Após a contagem e medição das raízes, as mesmas foram extraídas dos alporques e acondicionadas em sacos de papel e submetidas a secagem em estufa a $65 \pm 0,5^{\circ} \mathrm{C}$ até atingirem massa constante, por 72 horas. Em seguida, foi obtida a massa seca de raízes em balança com precisão de $0,001 \mathrm{~g}$.

O delineamento experimental utilizado foi o de blocos inteiramente casualizados (DBC), em esquema fatorial de dois fatores: 6 × 2 (6 substratos x 2 concentrações de AIB), com oito repetições, onde cada parcela foi constituída de um alporque, totalizando 96 parcelas.

Em virtude dos dados não atenderem aos requisitos de homogeneidade de variância e normalidade, mesmo após serem transformados, foi utilizada a estatística não paramétrica com a aplicação do teste de Kruskal-Wallis. As análises foram realizadas com auxílio estatístico ACTION versão 2.5 (ESTATCAMP, 2013), ao nível de significância de $5 \%$.

\section{RESULTADOS E DISCUSSÕES}

Os tratamentos com o substrato pó da casca de coco verde e rejeito de vermiculita, ambos associados ao uso do indutor de enraizamento (AIB), promoveram maior velocidade e porcentagem de enraizamento (Tabela 2).

Tabela 2. Porcentagens totais acumuladas de enraizamento em função do substrato e doses de AIB em alporques de $C$. quercifolius.

\begin{tabular}{|c|c|c|c|c|c|c|c|c|c|c|c|c|}
\hline \multirow{2}{*}{ Substratos* } & \multirow{2}{*}{ Doses de AIB } & \multicolumn{11}{|c|}{ Tempo após a realização das alporquias (dias) } \\
\hline & & 21 & 28 & 35 & 42 & 49 & 56 & 63 & 70 & 77 & 84 & 90 \\
\hline \multirow{2}{*}{$\mathrm{FC}$} & Testemunha $\left(0,0 \mathrm{~g} \mathrm{~L}^{-1}\right)$ & - & - & - & - & - & - & - & - & - & - & - \\
\hline & $\operatorname{AIB}\left(6,0 \mathrm{~g} \mathrm{~L}^{-1}\right)$ & - & - & - & - & 12,5 & 12,5 & 12,5 & 12,5 & 12,5 & 12,5 & 12,5 \\
\hline \multirow{2}{*}{$\mathrm{PC}$} & Testemunha $\left(0,0 \mathrm{~g} \mathrm{~L}^{-1}\right)$ & - & - & - & - & - & - & - & - & - & - & 12,5 \\
\hline & $\operatorname{AIB}\left(6,0 \mathrm{~g} \mathrm{~L}^{-1}\right)$ & 12,5 & 12,5 & 12,5 & 12,5 & 12,5 & 12,5 & 12,5 & 12,5 & 12,5 & 12,5 & 50,0 \\
\hline \multirow{2}{*}{ RV } & Testemunha $\left(0,0 \mathrm{~g} \mathrm{~L}^{-1}\right)$ & - & - & - & - & - & - & - & - & 12,5 & 12,5 & 37,5 \\
\hline & $\operatorname{AIB}\left(6,0 \mathrm{~g} \mathrm{~L}^{-1}\right)$ & - & 12,5 & 12,5 & 12,5 & 25,0 & $25,, 0$ & 25,0 & 25,0 & 25,0 & 37,5 & 50,0 \\
\hline \multirow{2}{*}{$1 / 2 \mathrm{FC}+1 / 2 \mathrm{RV}$} & Testemunha $\left(0,0 \mathrm{~g} \mathrm{~L}^{-1}\right)$ & - & - & - & - & - & - & - & - & - & - & - \\
\hline & $\operatorname{AIB}\left(6,0 \mathrm{~g} \mathrm{~L}^{-1}\right)$ & - & - & 25,0 & 25,0 & 25,0 & 25,0 & 25,0 & 25,0 & 25,0 & 25,0 & 37,5 \\
\hline \multirow{2}{*}{$1 / 2 \mathrm{PC}+1 / 2 \mathrm{RV}$} & Testemunha $\left(0,0 \mathrm{~g} \mathrm{~L}^{-1}\right)$ & - & - & - & - & - & 12,5 & 12,5 & 12,5 & 12,5 & 12,5 & 12,5 \\
\hline & $\operatorname{AIB}\left(6,0 \mathrm{~g} \mathrm{~L}^{-1}\right)$ & - & - & - & - & - & 12,5 & 25,0 & 25,0 & 25,0 & 25,0 & 25,0 \\
\hline \multirow[b]{2}{*}{$1 / 3 \mathrm{FC}+1 / 3 \mathrm{PC}+1 / 3 \mathrm{RV}$} & Testemunha $\left(0,0 \mathrm{~g} \mathrm{~L}^{-1}\right)$ & - & - & 12,5 & 12,5 & 12,5 & 12,5 & 12,5 & 25,0 & 25,0 & 25,0 & 37,5 \\
\hline & $\operatorname{AIB}\left(6,0 \mathrm{~g} \mathrm{~L}^{-1}\right)$ & - & - & 12,5 & 12,5 & 25,0 & 25,0 & 25,0 & 25,0 & 25,0 & 25,0 & 25,0 \\
\hline
\end{tabular}

* FC: Fibra de coco; PC: Pó de coco; RV: Rejeito de vermiculita.

Estes tratamentos além de promover o maior índice de enraizamento, também aceleraram o início do enraizamento, que ocorreu aos 21 e 28 dias, o que pode ser explicado, em parte, pela interação positiva destes substratos com o indutor de enraizamento. Esses resultados corroboram com Farias Júnior et al. (2015), que constataram o início do enraizamento mais rápido em faveleira com uso de indutor de enraizamento.

Lucena et al. (2014) constataram que mesmo com o uso de AIB na mesma concentração $\left(6,0 \mathrm{~g} \mathrm{~L}^{-1}\right)$, o aparecimento de raízes iniciou mais tarde, aos 42 dias após a realização dos alporques em matrizes de Cnidoscolus quercifolius, porém, utilizando vermiculita como substrato e em um período de avaliação com menor pluviosidade. Em condições semelhantes aos autores citados, Campos et al. (2015) relataram que as primeiras raízes apareceram na superfície dos substratos aos 42 dias após a realização das alporquias utilizando os substratos vermiculita e orgânico comercial Plantmax ${ }^{\circledR}$. Quanto maior a velocidade de enraizamento do alporque melhor para sua sobrevivência, porque diminui o tempo de exposição do mesmo às 
condições adversas do ambiente, notadamente, quebra do ramo e ataques de animais.

Embora o enraizamento com o substrato pó da casca de coco verde com AIB se iniciasse antes, a velocidade de enraizamento foi superior, com o uso do rejeito de vermiculita com AIB (Tabela 2). Diante destes resultados, observa-se que o uso do rejeito é mais vantajoso em relação ao pó, que tem uma maior velocidade de enraizamento, porém, há o inconveniente do problema da alta densidade do rejeito, que provoca a quebra de alporques, como constatado neste estudo e por Farias Júnior et al. (2015). O uso das composições (1/2FC+1/2 RV; $1 / 2 \mathrm{PC}+1 / 2$ RV e $1 / 3 \mathrm{FC}+1 / 3 \quad \mathrm{PC}+1 / 3 \quad \mathrm{RV}$ ) associadas ao $\mathrm{AIB}$ é promissora por promover velocidade de enraizamento superior ao PC puro, ao mesmo tempo, possui densidades bem inferiores ao rejeito.

Os tratamentos que receberam AIB foram superiores àqueles que não receberam (Tabela 2), exceto o substrato composto por $1 / 3 \mathrm{FC}+1 / 3 \mathrm{PC}+1 / 3$ RV que sem a adição do indutor, aos 90 dias, apresentou uma porcentagem de enraizamento $(37,5 \%)$ superior ao mesmo composto com a adição do indutor AIB (25\%). Uma possível explicação deste fato isolado é a influência de fatores não controlados, uma vez que, em outras variáveis discutidas adiante, mostra-se a superioridade do AIB, independente do substrato utilizado.

Resultados inferiores ao presente estudo foram obtidos por Danner et al. (2006) que relataram tendência de eficiência do AIB na indução de enraizamento em jabuticabeira (Plinia trunciflora), aplicando concentração de $4,0 \mathrm{~g} \mathrm{~L}^{-1}$, porém, há necessidade de maior período de tempo (180 dias) para um bom enraizamento.

Quanto à resposta dos alporques aos tratamentos aplicados avaliado com atribuição notas, não foi constatada variação significativa para nenhuma das fontes de variação $(P>0,05)$. No entanto, em valores absolutos, com o uso do indutor de enraizamento $\operatorname{AIB}\left(6,0 \mathrm{~g} \mathrm{~L}^{-1}\right)$, foram obtidas melhores respostas (Tabela 3 ).

Tabela 3. Médias de notas, comprimento da maior raiz, número de raízes e massa seca de raízes, para os fatores substrato e AIB, após 90 dias da realização das alporquias em C. quercifolius.

\begin{tabular}{|c|c|c|c|c|}
\hline Substratos* & Notas $* *$ & $\begin{array}{c}\text { Comprimento da maior } \\
\text { raiz }(\mathrm{cm})\end{array}$ & Número de raízes & $\begin{array}{c}\text { Massa seca de raízes } \\
(\mathrm{g})\end{array}$ \\
\hline FC & $1,00 \mathrm{a}$ & $0,75 \mathrm{a}$ & $0,44 \mathrm{a}$ & $0,46 \mathrm{a}$ \\
\hline $\mathrm{PC}$ & $1,56 \mathrm{a}$ & $1,66 \mathrm{a}$ & $0,87 \mathrm{a}$ & $1,13 \mathrm{a}$ \\
\hline RV & $2,13 \mathrm{a}$ & $3,16 \mathrm{a}$ & $3,38 \mathrm{a}$ & $1,49 \mathrm{a}$ \\
\hline $1 / 2 \mathrm{FC}+1 / 2 \mathrm{RV}$ & $1,25 \mathrm{a}$ & $2,00 \mathrm{a}$ & $0,69 \mathrm{a}$ & $0,77 \mathrm{a}$ \\
\hline $1 / 2 \mathrm{PC}+1 / 2 \mathrm{RV}$ & $1,25 \mathrm{a}$ & $2,00 \mathrm{a}$ & $0,94 \mathrm{a}$ & $0,43 \mathrm{a}$ \\
\hline $1 / 3 \mathrm{FC}+1 / 3 \mathrm{PC}+1 / 3$ & $1,56 \mathrm{a}$ & $4,22 \mathrm{a}$ & $1,63 \mathrm{a}$ & $1,24 \mathrm{a}$ \\
\hline Testemunha $\left(0,0 \mathrm{~g} \mathrm{~L}^{-1}\right)$ & $1,33 \mathrm{~A}$ & $1,29 \mathrm{~B}$ & $0,42 \mathrm{~B}$ & $0,53 \mathrm{~B}$ \\
\hline $\operatorname{AIB}\left(6,0 \mathrm{~g} \mathrm{~L}^{-1}\right)$ & $1,58 \mathrm{~A}$ & $3,32 \mathrm{~A}$ & $2,23 \mathrm{~A}$ & $1,32 \mathrm{~A}$ \\
\hline
\end{tabular}

* FC: Fibra de coco; PC: Pó de coco; RV: Rejeito de vermiculita.

** Notas atribuídas em escala de 0 a 4; sendo 0 (zero), alporque sem calos; 1 (um), alporque com formação de calo; 2 (dois), alporque com primórdios radiciais; 3 (três), alporque com raiz até $4 \mathrm{~cm}$ e 4 (quatro), alporque com raiz maior que $4 \mathrm{~cm}$.

*** médias seguidas de mesma letra, não diferem entre si pelo teste de Kruskal-Wallis, ao nível de significância de 5\% (P >0,05).

Smarsi et al. (2008), também trabalhando com sistema de atribuição de notas, encontraram maior eficiência com a utilização de húmus combinada com concentrações entre 2,175 e $2,250 \mathrm{~g} \mathrm{~L}^{-1}$ de AIB na alporquia de lichieira (Litchi chinensis Sonn.).

Os substratos que proporcionaram as maiores médias quanto à resposta dos alporques aos tratamentos aplicados (nota) foram rejeito de vermiculita (RV), seguido do pó da casca de coco verde (PC) e a composição de 1/3 de fibra, 1/3 de pó e $1 / 3$ de rejeito de vermiculita. Resultados semelhantes foram obtidos por Farias Júnior et al. (2015) com o uso de rejeito de vermiculita como substrato na alporquia de faveleira, não constatando diferenças significativas para a variável resposta dos alporques aos tratamentos aplicados (nota) $(\mathrm{P}>$ $0,05)$.

Constatou-se variação significativa para o fator AIB $(\mathrm{P}<0,05)$, para o comprimento da maior raiz, indicando que a aplicação do regulador vegetal proporcionou um maior desenvolvimento da raiz, independentemente do substrato utilizado (Tabela $3)$. Estes resultados concordam com os resultados obtidos por Dutra et al. (2012), em que o uso de AIB na concentração de $6,0 \mathrm{~g} \mathrm{~L}^{-1}$ promoveu o crescimento e desenvolvimento do sistema radicial 
em alporques de umbuzeiro (Spondias tuberosa Arruda).

Leite et al. (2007), não observaram eficiência do AIB em pequizeiro (Caryocar brasiliense Cambess.) no comprimento da maior raiz/alporque, evidenciando que há variação genotípica

Embora, com efeito não significativo do fator substrato, em valores absolutos o substrato $1 / 3 \mathrm{FC}+1 / 3 \mathrm{PC}+1 / 3 \mathrm{RV}$ proporcionou uma melhor resposta dos alporques com relação ao comprimento de raízes $(4,22 \mathrm{~cm})$ (Tabela 3). Este resultado, em parte, pode ser explicado pela combinação favorável deste composto, reunindo a maior fertilidade do rejeito com a maior porosidade proporcionada pela adição da fibra e pó da casca de coco verde. Conforme salientaram Sampaio et al. (2008), estes materiais podem ser considerados como componentes fundamentais na composição de substratos usados na produção de mudas de Lycopersicon esculentum Mill.

De forma análoga ao comprimento da raiz, para a variável número de raízes, foi constatada diferença significativa apenas para o fator AIB, mostrando maior eficiência com o uso do indutor de enraizamento no incremento do número de raízes (Tabela 3). Também para esta variável, os substratos $\mathrm{RV}$ e $1 / 3 \mathrm{FC}+1 / 3 \mathrm{PC}+1 / 3 \mathrm{RV}$ apresentaram as maiores médias.

Para o número de raízes/alporques, foi encontrado resultado superior quando se usou $3,0 \mathrm{~g}$ Kg-1 de AIB, veiculadas em pasta de lanolina, na produção de mudas de Ginkgo biloba L., sendo a técnica de alporquia viável com o uso da fibra de casca de coco como substrato (BITENCOURT et. al., 2007).

A avaliação de massa seca das raízes utilizando AIB como indutor foi significativamente maior $(\mathrm{P}<$ 0,05), quando comparada com ausência de AIB (Tabela 3). Esse resultado foi semelhante aos obtidos por Costa et al. (2012), que obtiveram diferença significativa para massa seca das raízes na clonagem de lichieira (Litchi chinensis Sonn.), utilizando $50 \%$ de concentração de Stimulate ${ }^{\circledR}$. (citocinina: $0,09 \mathrm{~g} \mathrm{~L}^{-1}$; giberelina: $0,05 \mathrm{~g} \mathrm{~L}^{-1}$ ) e ácido indolcanoico: $0,05 \mathrm{~g} \mathrm{~L}^{-1}$ ), aplicado com auxílio de pincel.

Quanto aos substratos apesar de não apresentarem diferença significativa $(\mathrm{P}>0,05)$, os melhores resultados obtidos foram com o uso dos substratos RV, 1/3FC+1/3PC+1/3RV e PC, respectivamente (Tabela 3). Resultados semelhantes foram observados por Farias Júnior et al. (2015), em que o RV apresentou resultado superior à vermiculita na produção de massa seca de raízes de faveleira.

Finalmente, constata-se que a aplicação do AIB foi eficiente no incremento do comprimento, número e massa seca de raízes de Cnidoscolus quercifolius Pohl., fatores importantes na formação de mudas, além de promover o enraizamento mais rápido e uniforme. Isto é de suma importância, quando se utiliza a técnica clonal por alporquia em que as mudas são produzidas em matrizes diretamente no campo e ficam mais vulneráveis às condições adversas quanto à exposição aos fatores bióticos e abióticos.

Conforme salientado por Farias Júnior et al. (2015), o substrato rejeito de vermiculita teve um desempenho superior em todas as variáveis estudadas, influenciando significativamente a produção de massa seca radicial da faveleira, mostrando a importância como substrato alternativo para a produção de mudas, sobretudo pela fácil aquisição e baixo custo

No entanto, os autores salientaram um inconveniente com o uso deste substrato, na clonagem de plantas pelo processo da alporquia. Ele apresenta alta densidade, que pode provocar a quebra nos ramos alporcados, sugerindo a avaliação da composição deste substrato com outros de menor densidade, para atenuar este problema.

Diante disso, os resultados obtidos neste trabalho mostram que há viabilidade do uso dos substratos fibra e pó da casca de coco verde na composição com o rejeito de vermiculita, reduzindo a densidade do substrato e, consequentemente, contribuindo nas esferas econômica (menor custo), social e de forma efetiva com a solução da problemática provocada por estes resíduos no meio ambiente.

Em todas as variáveis analisadas, as maiores médias foram observadas com o uso do rejeito de vermiculita e a combinação balanceada da fibra da casca de coco verde, pó da casca de coco verde e rejeito de vermiculita. No entanto, este estudo evidencia que há necessidade de avaliar outras composições entre estes substratos alternativos, para encontrar as proporções ideais para maximizar a eficiência na produção de mudas pela técnica de alporquia para a faveleira, nas condições adversas que estas plantas ocorrem no Bioma Caatinga.

A continuidade destes estudos irá contribuir num futuro próximo com a melhoria de vida dos herbolários que poderão explorar a planta medicinal de uma forma sustentável e as populações locais inseridas no semi-árido serão contempladas com a melhoria da saúde familiar, agregação de renda, redução do desemprego e da fome de milhares de famílias na região nordeste do Brasil, e também com a redução dos impactos ambientais provocados pela exploração da planta e descarte dos resíduos de coco e vermiculita como ocorre na atualidade.

\section{CONCLUSÕES}


De um modo geral, o substrato com $1 / 3$ de fibra da casca de coco verde $+1 / 3$ de pó da casca de coco verde $+1 / 3$ de rejeito de vermiculita é o mais eficiente para o enraizamento de alporques em ramos de faveleira e de baixo custo.

$\mathrm{O}$ uso do AIB foi eficiente no incremento do comprimento, número e massa seca de raízes de Cnidoscolus quercifolius.

\section{REFERÊNCIAS}

AGRA, M.F.; BARACHO, G. S.; BASÍlIO, I. J. D.; NURIT, K.; COELHO, V. P.; BARBOSA, D. A. Sinopse da flora medicinal do cariri paraibano. Oecolologia Brasiliensis, v.11, n.3, p.323-330, 2007.

BITENCOURT, J.; MAYER, J. L. S.; ZUFFELLATORIBAS, K. C. Propagação vegetativa de Ginkgo biloba por alporquia. Revista Brasileira de Plantas Medicinais, v.9, n.2, p.71-74, 2007.

BRITO, E. A.; ARRIEL, E. F.; SANTOS, D. R.; NÓBREGA, A. M. F.; FARIAS JÚNIOR, J. A. Enraizamento e desenvolvimento de mudas de Cnidoscolus quercifolius, clonadas pela técnica de alporquia. Revista Verde, v.9, n.1, p.254-264, 2014. DOI. http://www.gvaa.com.br/revista/index.php/RVADS/ article /view/2353/2231.

CAMPOS, G. N. F.; ARRIEL, E. F.; NOBERTO, M. N. S.; FARIAS JUNIOR, J. A.; SILVA, V. V. M.; FREIRE, A. L. O. Clonagem de Cnidoscolus quercifolius por alporquia. Ciência Florestal, v. 25, n. 3, p. 743-749, 2015. DOI: $10.5902 / 1980509819677$.

CARRIJO, O. A.; LIZ, R. S.; MAKISHIMA, N. Fibra da casca do coco verde como substrato agrícola. Revista Horticultura Brasileira, v. 20, n. 4, p. 533-535, 2002.

COSTA, A. C.; RAMOS, J. D.; NETO, A. C.; BORGES, D. I.; MENEZES, T. P.; RAMOS, P. S. Alporquia e regulador de crescimento na propagação de lichieira. Revista de Ciências Agrárias, v. 55, n.1, p.40-43, 2012. Doi: 10.4322/rca.2012.035

DANNER, M. A.; CITADIN, I.; FERNANDES, J.; FERNANDES JÚNIOR, A. A.; ASSMANN, A. P.; MAZARO, S. M.; DONAZZOLO, J.; SASSO, S. A. Z. Enraizamento de jabuticabeira (Plinia trunciflora) por mergulhia aérea. Revista Brasileira de Fruticultura, v.28, n.3, p.530-532, 2006. DOI: 10.1590/S010029452006000300043.

DUTRA T. R.; MASSAD, M. D.; SARMENTO, M. F. Q.; OLIVEIRA, J. C. Ácido indolbutírico e substratos na alporquia de umbuzeiro. Revista Pesquisa Agropecuária Tropical, v.42, n.4, p.424-429, 2012. DOI: $10.1590 /$ S $1983-40632012000400010$

ESTATCAMP. Software Action, 2013. Disponível em <www.portalaction.com.br>. Acesso em: 05 jul. 2013.
FARIAS JÚNIOR, J. A.; ARRIEL, E. F.; LÚCIO, A. M. F. N.; FREIRE, A. L. F.; SANTOS, R. V.; LUCENA, R. J. Clonagem de Cnidoscolus quercifolius por alporquia, utilizando rejeito de vermiculita e diferentes concentrações de AIA. Pesquisa Florestal Brasileira, v.35, n.81, p.35-40, 2015 . DOI: 10.4336/2015.pfb.35.81.499.

FRANÇA, I. S. X.; SOUZA, J. A.; BAPTISTA, R. S.; BRITTO, V. R. S. Medicina popular: benefícios e malefícios das plantas medicinais. Revista Brasileira de Enfermagem, v.61, n.2, p.201-208, 2008. DOI: 10.1590/S0034-71672008000200009.

GOMES, L. M. A.; ANDRADE, T. M.; SILVA, J. C.; LIMA, J. T.; QUINTANS-JUNIOR, L. J.; ALMEIDA, J. R. G. Phytochemical screening and anti-inflammatory activity of Cnidoscolus quercifolius (Euphorbiaceae) in mice. Pharmacognosy Research, v.6, n.4, p.345-349, 2014.

8490.138290 PMID: 25276074.

DOI: $10.4103 / 0974-$

LEITE, G. L. D.; VELOSO, R. V. S.; CASTRO, A. C. R.; LOPES, P. S. N.; FERNANDES, G. W. Efeito do AIB sobre a qualidade e fitossanidade dos alporques de influência da Caryocar brasiliense CAMB (CARYOCARACEAE). Revista Árvore, v.31, n.2, p.315-320, 2007. DOI: 10.1590/S010067622007000200014 .

LUCENA, R. J.; PIMENTA, M. A. C.; ARRIEL, E. F.; LUCENA, R. J.; ANTONIO LUCINEUDO OLIVEIRA FREIRE, A. L. O. Níveis de anelamento, AIB e proteção do substrato na clonagem de Cnidoscolus quercifolius por alporquia. Revista Verde, v.9, n.2, p.173-184, 2014.

MANTOVANI, N. C.; GRANDO, M. F.; XAVIER, A.; OTONI, W. C. Resgate vegetativo por alporquia de genótipos adultos de urucum (Bixa orellana 1.). Ciência Florestal, v.20, n.3, p.403-410, 2010. DOI: $10.5902 / 198050982055$

MARREIROS, N. A.; FERREIRA, E. C.; LUCENA, C. M.; LUCENA, R. F. P. Conhecimento botânico tradicional sobre plantas medicinais no semiárido da Paraíba (Nordeste, Brasil). Revista Ouricuri, v.5, n.1, p.110-144, 2015.

MAURYA, R. P.; LEWIS, D. M.; CHANDLER, J. A. Studies on the propagation of jamaican ackee (Blighia sapida L.) by Air-layering. Hortscience, v.48, n.10, p.1298-1300, 2013.

PAULINO, R. C.; HENRIQUES, G. P. S. A.; COELHO, M. F. B.; ARAÚO, P. V. N. Riqueza e importância das plantas medicinais do Rio Grande do Norte. Revista de Biologia e Ciências da Terra, v.11, n.1, p.157-168, 2011.

PIMENTA, M. A. C.; ARRIEL, E.F.; SANTOS D. R.; SANTOS Y. M.; LUCENA, E. O. Clonagem por 
alporquia de Cnidoscolus quercifolius Pohl. utilizando auxina natural. Revista Verde, v.9, n.2, p.83-94, 2014.

REHMAN, M.; AWAN, A. A.; KHAN, O.; HAQ, I. Response of five cultivars to air-layering at various timings. Journal Agriculture Science, v. 50, n.4, p.555558, 2013.

ROQUE, A. A.; ROCHA, R. M.; LOIOLA, M. I. B. Uso e diversidade de plantas medicinais da Caatinga na comunidade rural de Laginhas, município de Caicó, Rio Grande do Norte (Nordeste do Brasil). Revista Brasileira de Plantas Medicinais, v.12, n.1, p.31-42, 2010.

ROSA, M. F. SANTOS, F. J. S.; MONTENEGRO, A. A. T.; ABREU, F. A. P.; CORREIA, D.; ARAÚJO, F. B.; NORÕES, E. R. Utilização do pó de coco verde na germinação de alface hidropônico. Horticultura Brasileira, v.19, n.2, p.294, 2001.

SAMPAIO R. A.; RAMOS, S. J.; GUILHERME, D. O.; COSTA, C. A.; FERNANDES, L. A. Produção de mudas de tomateiro em substratos contendo fibra de coco e pó de rocha. Revista Horticultura Brasileira, v.26, n.4, p.499503, 2008 .
SILVA, L. L. H.; ARRIEL, E. F.; LUCENA, R. J.; PIMENTA, M. A. C; BEZERRA, R. M. B. Ácido indol acético e ácido indol butírico na clonagem de Cnidoscolus quercifolius pelo processo de macroestaquia. Revista Verde, v.8, n.2, p.90-96, 2013.

SINGH, S.; ANSARI, S. A. Callus formation impedes adventitious rhizogenesis in air layers of broadleaved tree species. Annals of Forest Research, v.57, n.1, p.47-54, 2014. DOI: $10.15287 /$ afr.2014.189

SMARSI, R. C.; CHAGAS, E. A.; REIS, L. L.; OLIVEIRA, G. F.; MENDONÇA, V.; TROPALDI, L.; PIO, R.; SCARPARE FILHO, J. A. Concentrações de ácido indolbutírico e tipos de substrato na propagação vegetativa de lichia. Revista Brasileira de Fruticultura, v.30, n.1, p.7-11, 2008. DOI: 10.1590/S010029452008000100004 .

VIEIRA, E. V. Caracterização e processamento de vermiculitas para fluídos de perfuração de petróleo. In: Insumos Minerais para Perfuração de Petróleo, 2003. cap. 4 , p. 62-79. 